\title{
PATROCÍNIO ESPORTIVO E COMUNICAÇÃO DE MARCA: PERSPECTIVAS DE PATROCINADORES, GESTORES DE MARKETING ESPORTIVO E ATLETAS BRASILEIROS DO SURFE PROFISSIONAL
}

Marco Antonio de Moraes Ocke Doutorado em Administração - FEA/USP Universidade Federal de Santa Catarina marco.ocke@ufsc.br

Marcos Abílio Bosquetti Doutorado em Administração - FEA/USP Universidade Federal de Santa Catarina marcos.bosquetti@ufsc.br

Gabriel Vicente Alexandre Bacharelado em Administração - CAD/UFSC Universidade Federal de Santa Catarina gabrielvicente2609@gmail.com

\section{Resumo}

Objetivo: Discutir a perspectiva de marcas patrocinadoras, empresários de marketing esportivo e atletas brasileiros do surfe profissional no que tange objetivos em comum, formatos de comunicação e ativações de marca que gerem maior retorno para patrocinadores e patrocinados.

Metodologia/abordagem: De caráter qualitativo descritivo, foram realizadas entrevistas em profundidade, sendo duas com gestores de marcas patrocinadoras; duas com empresários de marketing esportivo; duas com atletas brasileiros competidores na primeira divisão do surfe mundial. Na análise triangulada de dados foi utilizado o software Voyant Tools.

Originalidade/relevância: $O$ patrocínio é um dos principais formatos de investimento em comunicação de marca no marketing esportivo, entretanto, poucos trabalhos tratam de patrocínio em atletas trazendo à tona perspectivas de marcas, intermediários e atletas.

Principais resultados: Para as marcas patrocinadoras, o principal vetor de atratividade em iniciativas de patrocínio nos atletas é o desempenho obtido nos campeonatos associado à capacidade de o atleta proporcionar visibilidade à marca. Para atletas e empresários, o essencial é o apoio financeiro visando a manutenção de equipe técnica e o bom desempenho nas competições, e, como consequência, a associação da imagem vencedora entre patrocinador e patrocinado.

Contribuições teóricas: Proposição de utilização de ativações de marca que possam ampliar a experiência do consumo esportivo e métricas para controlar e avaliar o retorno do investimento em patrocínio.

Palavras-chave: Patrocínio esportivo. Comunicação de marca. Surfe. Atletas.

\section{Cite como}

American Psychological Association (APA)

Ocke, M. A. M., Bosquetti, M. A., \& Alexandre, G. V. (2021, set./dez.). Patrocínio esportivo e comunicação de marca: perspectivas de patrocinadores, gestores de marketing esportivo e atletas brasileiros do surfe profissional.

PODIUM Sport, Leisure and Tourism Review, São Paulo, 10(3), 21-51. https://doi.org/10.5585/podium.v10i3.17001 
Ocke, M. A. M., Bosquetti, M. A., \& Alexandre, G. V. (2021, set./dez.). Patrocínio esportivo e comunicação de marca: perspectivas de patrocinadores, gestores de marketing esportivo e atletas brasileiros do surfe profissional

\title{
SPORTS SPONSORSHIP AND BRAND COMMUNICATION: PERSPECTIVES OF SPONSORS, SPORTS MARKETING MANAGERS AND BRAZILIAN PROFESSIONAL SURFING ATHLETES
}

\begin{abstract}
Objective: Discuss the perspective of sponsoring brands, sports marketing entrepreneurs and Brazilian professional surfing athletes regarding common goals, communication formats and brand activations that generate greater return for sponsors and sponsees.

Methodology: Qualitative and descriptive, in-depth interviews were conducted, two with sponsoring brand managers; two with sports marketing entrepreneurs; two with Brazilian athletes competing in the first division of world surfing. In the triangulated data analysis, the Voyant Tools software was used. Originality and relevance: Sponsorship is one of the main formats of investment in brand communication in sports marketing, however, few works deal with sponsorship in athletes bringing up perspectives of brands, intermediaries and athletes.

Results: For sponsoring brands, the main vector of attractiveness in sponsorship initiatives in athletes is the performance obtained in championships associated with the athlete's ability to provide visibility to the brand. For athletes and entrepreneurs, the essential thing is the financial support aimed at maintaining the technical team and the good performance in the competitions, and, as a consequence, the association of the winning image linking sponsor and sponsee.

Theoretical contributions: Proposition to use brand activations that can expand the experience of sports consumption and metrics to control and evaluate the return on investment in sponsorship.

Keywords: Sports sponsorship. Brand communication. Surf. Athletes.

\section{PATROCINIO DEPORTIVO Y COMUNICACIÓN DE MARCA: PERSPECTIVAS DE PATROCINADORES, GERENTES DE MARKETING DEPORTIVO Y ATLETAS BRASILEÑOS DE SURF PROFESIONAL}

\section{Resumen}

Objetivo: Discutir la perspectiva de marcas, emprendedores de marketing deportivo y atletas brasileños de surf profesionales con respecto a objetivos comunes, formatos de comunicación y activaciones de marca que generan un mayor retorno para patrocinadores y patrocinados.

Metodología: se realizaron entrevistas cualitativas y descriptivas en profundidad, dos con gerentes de marca patrocinadores; dos con empresarios de marketing deportivo; dos con atletas brasileños compitiendo en la primera división del surf mundial. En el análisis de datos triangulados, se utilizó el software Voyant Tools.

Originalidad y Relevancia: el patrocinio es uno de los principales formatos de inversión en comunicación de marca en marketing deportivo, sin embargo, pocos trabajos tratan con el patrocinio en atletas que traen perspectivas de marcas, intermediarios y atletas.

Resultados: Para las marcas patrocinadoras, el principal vector de atractivo en las iniciativas de patrocinio en los atletas es el rendimiento obtenido en los campeonatos asociados con la capacidad del atleta para proporcionar visibilidad a la marca. Para los atletas y empresarios, lo esencial es el apoyo financiero destinado a mantener el equipo técnico y el buen desempeño en las competiciones, y, como consecuencia, la asociación del patrocinador ganador y el patrocinado.

Contribuciones teóricas: propuesta de utilizar activaciones de marca que pueden ampliar la experiencia del consumo deportivo y las métricas para controlar y evaluar el retorno de la inversión en patrocinio.

Palabras clave: Patrocinio desportivo. Comunicación de marca. Surf. Atletas. 
Ocke, M. A. M., Bosquetti, M. A., \& Alexandre, G. V. (2021, set./dez.). Patrocínio esportivo e comunicação de marca: perspectivas de patrocinadores, gestores de marketing esportivo e atletas brasileiros do surfe profissional

\section{Introdução}

As atividades esportivas motivam a integração entre as pessoas gerando envolvimento com públicos demograficamente e economicamente de diferentes níveis tornando os investimentos em marketing esportivo uma opção relevante para as atividades administrativas de organizações atuantes em diferentes mercados (Smith \& Stewart, 2007). Neste sentido, as empresas têm utilizado o marketing esportivo como uma ferramenta para alavancar marcas, criando oportunidades em novos mercados a fim de consolidar e fidelizar clientes. Dentre as atividades de marketing esportivo destacam-se as ações de patrocínio, considerado o principal investimento, por ser um formato de comunicação de marketing capaz de impactar significativamente a audiência pelo fato de as mensagens se aproximarem dos consumidores de forma eficiente, complementando outros formatos de comunicação integrada de marketing, uma vez que o patrocinador, seja ele de um evento, atleta ou equipe, tem como objetivo fazer com que sua marca ganhe notoriedade por meio da construção e gerenciamento de sua imagem (Morgan \& Summers, 2008; Soderman \& Dolles, 2010; Mazzei \& Rocco, 2017).

O planejamento estratégico de patrocínio esportivo, aliado à gestão da identidade e imagem da marca, coaduna uma combinação efetiva para estabelecer uma parceria profícua entre patrocinador e patrocinado. Parceria na qual o patrocinador expõe sua marca, produto ou serviço e, em contrapartida, o patrocinado potencializa seu valor agregado estabelecendo uma associação de imagens que impacta positivamente o comportamento do consumidor esportivo. Por meio de patrocínios, é possível associar empresas, marcas ou produtos a times, seleções esportivas, ou mesmo a atletas individuais (Soderman \& Dolles, 2010; Horowitz, 2014; Parolini \& Rocco Junior, 2015). No caso específico do patrocínio em atletas, as empresas identificam aqueles aderentes às imagens das marcas e em constante exposição na mídia, resultando no aumento da visibilidade do patrocinador.

A capacidade de um atleta expor uma marca é algo que impacta diretamente nas decisões de patrocínio, uma vez que os consumidores se identificam e se inspiram nestes indivíduos, desejando as marcas e produtos por eles comunicados. $\mathrm{O}$ endosso de um produto ou marca por profissionais do mundo do esporte exerce um efeito substancial de transferência da imagem do atleta para a marca patrocinadora, ou seja, levando o consumidor a comprar o produto e expressar sua preferência e fidelidade à marca do patrocinador (Melo Neto, 2000). Em geral, durante o consumo da experiência esportiva, o consumidor tende a estar mais aberto à mensagem da marca se comparado a outros pontos de contato como propaganda e 
Ocke, M. A. M., Bosquetti, M. A., \& Alexandre, G. V. (2021, set./dez.). Patrocínio esportivo e comunicação de marca: perspectivas de patrocinadores, gestores de marketing esportivo e atletas brasileiros do surfe profissional

merchandising, por exemplo, assim, a associação de uma marca a um atleta cria uma relação de cumplicidade da empresa com a performance esportiva (Afif, 2000; Silva \& Las Casas, 2017).

O patrocínio esportivo pode oferecer aos profissionais de marketing a oportunidade de se dirigirem a novos públicos-alvo, gerenciarem suas marcas e melhorarem suas imagens corporativas (Ferkins \& Garland, 2006). Mazzei e Rocco (2017) indicam que o patrocínio, de equipes ou esportes, por parte das empresas foca especificamente na expansão do conhecimento do nome do patrocinador e a associação com a qualidade percebida da marca com o time ou modalidade esportiva. Apesar de ser uma estratégia de marketing adotada por inúmeras empresas para criar relações dinâmicas com os consumidores (Farrelly \& Quester, 2005), um desafio do planejamento de patrocínio é a estrutura de mensuração dos resultados, uma vez que, apesar do aumento crescente da prática de patrocínio esportivo, há situações em que os resultados obtidos por meio de patrocínios não são avaliados e mensurados adequadamente (Roy \& Cornwell, 2004; Horowitz, 2014).

Neste cenário, este artigo delimita como objeto de estudo as relações sob a perspectiva de marcas patrocinadoras, empresários de marketing esportivo e atletas brasileiros do surfe profissional por meio do seguinte problema de pesquisa: quais os elementos comuns da relação entre as partes envolvidas sob perspectivas de marcas patrocinadoras, empresários de marketing esportivo e atletas brasileiros do surfe profissional? Desta forma, a pesquisa identifica elementos comuns às entidades envolvidas no que tange seus objetivos mercadológicos e profissionais, formatos de comunicação e ativação de marca e retorno de investimento proporcionado pelos atletas para as marcas patrocinadoras. Para tanto, foram realizadas no segundo semestre de 2019, seis entrevistas em profundidade, sendo duas entrevistas com gestores de marcas que patrocinam atletas profissionais, Billabong e Snapy Surfboards; duas entrevistas com empresários de marketing esportivo diretores das empresas G8 Sports Entertainment e Flow Sports Management; duas entrevistas com atletas brasileiros competidores na primeira divisão do surfe profissional mundial, Yago Dora e Michael Rodrigues.

Os resultados indicam que as três partes envolvidas no patrocínio possuem grande alinhamento em relação aos seus objetivos. Para os gestores de marcas patrocinadoras, o principal vetor de atratividade para iniciativas de patrocínio nos atletas é o desempenho obtido nos campeonatos, associado à capacidade de o atleta proporcionar visibilidade à marca no ambiente digital, em ativações em lojas físicas e demais pontos de contato com o público-alvo. 
Ocke, M. A. M., Bosquetti, M. A., \& Alexandre, G. V. (2021, set./dez.). Patrocínio esportivo e comunicação de marca: perspectivas de patrocinadores, gestores de marketing esportivo e atletas brasileiros do surfe profissional

Para atletas e gestores de carreira, o essencial é o apoio financeiro visando a manutenção de equipe técnica e o bom desempenho nas competições, e, como consequência, a capitalização da associação da imagem vencedora entre patrocinador e patrocinado. Ainda, destacam-se nos resultados discutidos, a utilização limitada de ativações de marca que possam ampliar a experiência do consumo esportivo por meio da relação entre atletas e consumidores, e a falta de modelos e métricas quantitativas para controlar e avaliar o retorno do investimento em patrocínio.

\section{Patrocinio esportivo}

Os administradores e profissionais de marketing esportivo têm contribuído para o desenvolvimento do conhecimento sobre patrocínio esportivo, tanto ou mais que a comunidade científica, entretanto, observa-se no mercado como na literatura, que o patrocínio é o meio mais conhecido e utilizado, recebendo maior aporte de investimentos em marketing esportivo. Este investimento, em espécie ou outro meio com valor mensurável, visa garantir o acesso do patrocinador ao potencial comercial que possa ser explorado associado ao evento, equipe ou atleta patrocinado (Fahy, Farrelly, \& Quester, 2004). De qualquer forma, tanto o mercado esportivo como a literatura indicam que a essência do mecanismo de patrocínio consiste em aumentar a ligação entre patrocinador, patrocinado, consumidor e vendas, por meio de ações ligadas ao patrocínio e que ofereçam experiências aos envolvidos, criando uma forte relação com a marca patrocinadora (Parolini \& Rocco Junior, 2015).

O patrocínio tem como características básicas a valorização e o posicionamento da marca patrocinadora de um time ou esporte em seus mercados-alvo integrado à suas metas empresariais gerais e ao modo de fazer negócios (Ottoni \& Montagner, 2004). Assim, o patrocínio esportivo é uma forma usada por empresas para expor suas marcas em eventos, em atletas ou grupos de atletas para, assim, associá-las àquilo que está sendo patrocinado (Gwinner \& Swanson, 2003). Neste cenário, muitas empresas buscam patrocínios visando o aumento do conhecimento da marca, ou ainda estabelecer, fortalecer ou modificar sua imagem por meio do objeto patrocinado (Crowley, 1991; Meenaghan, 1991), uma vez que o patrocínio esportivo aumenta a frequência de exposição das mensagens de marketing, mantendo vínculos e com grande impacto sobre a atitude do consumidor (Smolianov \& Shilbury, 2005). Além disso, o patrocínio esportivo deve ser capaz de auxiliar a empresa a atingir objetivos específicos, dentre os quais: aumento de vendas; conquista de mercado; conhecimento, visibilidade e promoção de 
Ocke, M. A. M., Bosquetti, M. A., \& Alexandre, G. V. (2021, set./dez.). Patrocínio esportivo e comunicação de marca: perspectivas de patrocinadores, gestores de marketing esportivo e atletas brasileiros do surfe profissional

produtos e/ou serviços da marca/empresa; influência da percepção e atitude de consumidores; realização de ações de hospitalidade corporativa; alcance de formadores de opinião por meio de exposição na mídia; criação de uma relação profícua com stakeholders (Brown, 2000; Meenaghan, 2001; Alexander, 2009; Horowitz, 2014).

Os patrocínios esportivos podem ir além da exposição da marca que é potencializada pela cobertura midiática de diferentes eventos e campeonatos esportivos e da possibilidade de explorar endosso dos produtos por parte de equipes e atletas (Chakraborti \& Roy, 2013). Assim, algumas empresas utilizam o patrocínio esportivo como parte de estratégias de marketing experiencial uma vez que a ativação de marcas em patrocínio esportivo está baseada na estratégia de alimentar a conexão entre patrocinador, patrocinado, consumidor e vendas, por meio de ações que ampliem a experiência ofertada aos envolvidos, criando uma relação mais próxima entre o patrocinado e a marca patrocinadora, tendo o consumidor esportivo no centro desta catarse (Silva \& Las Casas, 2017). Navarro, Sicilia e Delgado-Ballester (2009) reforçam que no contexto do consumo esportivo, os indivíduos estão mais abertos aos estímulos e emoções intrínsecas ao esporte, favorecendo a construção de conexões positivas entre marcas e consumidores. Corroboram neste sentido, Yamamoto, Cordova \& Mazzei (2018), destacando que tais experiências estão relacionadas com espaços vips em competições, interações que aproximam atletas e admiradores, premiações em eventos entre outras ativações de marca menos convencionais.

Sá e Almeida (2012) apresentam um modelo sustentado por quatro pilares fundamentais: objetivo, seleção, ativação e mensuração. Tais pilares fazem parte do processo de tomada de decisão em relação ao patrocínio esportivo. Todos são executados em sequência, porém, interligados de uma forma sistêmica (Parolini \& Rocco Junior, 2015). Ainda, todas as decisões devem estar de acordo com os objetivos da empresa patrocinadora, bem como serem coerentes com público-alvo que a marca deseja atingir uma vez que o investimento em patrocínio envolve, geralmente, o repasse de recursos financeiros de uma organização para uma atividade que será basicamente um veículo de comunicação de marca (Meenaghan, 2001). Por meio de patrocínios, é possível associar empresas, marcas ou produtos a equipes e eventos esportivos, ou mesmo a atletas individuais (Soderman \& Dolles, 2010). O patrocínio esportivo oferece aos profissionais de marketing a oportunidade de se comunicarem com seus públicos de forma menos invasiva, construírem e gerenciarem suas marcas e imagens corporativas (Ferkins \& Garland, 2006). 
Ocke, M. A. M., Bosquetti, M. A., \& Alexandre, G. V. (2021, set./dez.). Patrocínio esportivo e comunicação de marca: perspectivas de patrocinadores, gestores de marketing esportivo e atletas brasileiros do surfe profissional

O objetivo de patrocinar o esporte pode apresentar diferenças, em especial quando falamos em sua aplicabilidade. Neste sentido, Geng, Burton e Blakemore (2002) contribuem ao classificarem esta ferramenta de comunicação de marca de acordo com seus tipos: os patrocínios de notoriedade, de credibilidade ou imagem. Para os autores, o primeiro atende ao objetivo de elevação do conhecimento da empresa ou dos seus produtos; o segundo propõe promover o reconhecimento e experiência da empresa na sua área de atuação; enquanto a terceira classificação busca reforçar a imagem da empresa ou seus produtos e marcas, com a formação de vínculo entre as imagens da marca e do esporte. Neste contexto, destaca-se também, a maneira como deverá ser a seleção do patrocínio, de acordo com dois pontos cruciais para a tomada de decisão: o que patrocinar (eventos, equipes, atletas) e qual modalidade esportiva a ser patrocinada. Independentemente da estrutura, objetivo ou formato, Fernandes (2009) descreve o patrocínio esportivo como um instrumento de comunicação de marca, onde a exposição de seu nome, identidade visual e/ou produto da empresa realiza-se por meio do esporte.

\subsection{Comunicação de marca por meio do patrocínio esportivo}

Considerando o composto de marketing, o patrocínio faz parte das estratégias de promoção, sendo que promover algo é complexo e vai muito além de simplesmente aparecer e persuadir as pessoas à consumidor algo, é preciso informar, interagir, persuadir e envolver (Morgan \& Summers, 2008). Esta abordagem é interessante para compreender a importância do patrocínio, já que neste tipo de ação promocional os consumidores são atingidos em um momento em que se encontram emocionalmente mais receptivos às mensagens e estímulos de marketing, diferentemente de formatos tradicionais como a propaganda (Navarro et al., 2009). O patrocínio esportivo está intimamente relacionado à visibilidade das organizações, por se comunicar eficazmente com seu público. Assim, trata-se de uma ferramenta de comunicação que contribui de forma eficiente com os esforços promocionais de relacionamento das organizações com seus públicos. Competição, orgulho, status, exposição, universalidade, envolvimento familiar e imagem são algumas das razões para o investimento neste formato de comunicação de marca (Gwinner \& Swanson, 2003).

Tal é a eficiência do patrocínio esportivo que pode ser apontado não apenas como uma ferramenta de comunicação, mas como uma forma de mídia alternativa, já que é capaz de sozinho promover uma marca junto ao seu público-alvo, gerando retorno sobre o investimento 
Ocke, M. A. M., Bosquetti, M. A., \& Alexandre, G. V. (2021, set./dez.). Patrocínio esportivo e comunicação de marca: perspectivas de patrocinadores, gestores de marketing esportivo e atletas brasileiros do surfe profissional

por meio de publicidade, imagem e aumento de vendas (Melo Neto, 1995). Para Bourg e Gouguet (2005), existem ao menos cinco razões que justificam os investimentos das grandes marcas em equipes esportivas profissionais: elevado índice de audiência esportiva em diferentes mídias; o estado de receptividade dos espectadores; a linguagem universal do esporte; a necessidade de estar presente em todos os mercados; a vontade de forjar para si uma imagem simpática e popular. Portanto, as marcas costumam explorar estes fatores para que possam se comunicar com stakeholders, seja por meio de uma mensagem, logomarca, slogan ou quaisquer fatores que sejam relacionados à patrocinadora.

As mensagens transmitidas por patrocínios esportivos chegam sutilmente e fixam-se na mente dos consumidores mediante associações, garantindo prestígio e credibilidade às marcas patrocinadoras. O que o patrocinador busca quando associa a sua marca a um esporte, uma equipe esportiva, uma competição ou um atleta é transmitir uma mensagem de dinamismo, agilidade, relacionada à emoção e à paixão (Afif, 2000). Esse é o tipo de ação que tem a capacidade de reforçar ou mesmo mudar as atitudes de um consumidor em relação a uma marca (Escobar, 2002). Mason (2005) declara ainda que a chave para a efetividade do patrocínio é o entendimento de como as atitudes do consumidor são formadas e alteradas e, neste sentido, Neiva e Mauro (2011) discorrem que quanto mais intensa for a atitude, maior será seu poder associativo em relação à oferta e mais fácil será sua recuperação da memória. Assim, com um maior recall de marca e uma atitude favorável estimulada no seu âmbito afetivo, o patrocínio esportivo tende a influenciar o comportamento de consumo no que tange à marca patrocinadora.

Rezende (2013) reforça que o patrocínio esportivo vai além de simplesmente colocar uma marca estampada em determinada modalidade, contabilizando posteriormente quantas vezes apareceu nos diversos meios de comunicação, ou seja, é fundamental que se perceba a sinergia entre a marca e a propriedade esportiva para controlar como, quando e onde investir em uma determinada plataforma. Assim, exposição de uma marca pode levar à mudança de atitude, por meio do princípio de que estímulos encontrados previamente são mais facilmente percebidos. Em linhas gerais, atitudes positivas em relação aos patrocinadores têm sido associadas com boas percepções e intenções favoráveis à compra dos produtos dos patrocinadores (Thompson \& Speed, 2000). No entanto, vale a ressalva de que a repetição na exposição da marca, quando considerada excessiva, pode alterar a atitude sobre ela de maneira negativa.

Importante ressaltar que ações de patrocínio agindo de forma isolada não são capazes de atingir objetivos de comunicação de marca, sendo essencial estabelecer associações de longo 
Ocke, M. A. M., Bosquetti, M. A., \& Alexandre, G. V. (2021, set./dez.). Patrocínio esportivo e comunicação de marca: perspectivas de patrocinadores, gestores de marketing esportivo e atletas brasileiros do surfe profissional

prazo entre empresa e esporte, além de grandes esforços de ativação, para se agregar valor e alterar a atitude do consumidor para com a marca patrocinadora. De qualquer forma, como propõem Giroux, Pons e Maltese (2017), ações de patrocínio parecem afetar os componentes da atitude por criar uma associação positiva entre consumidores e empresa. Assim, a atitude em relação a uma marca tem um forte impacto no comportamento de consumo, ou seja, atitudes positivas influenciariam favoravelmente a aquisição de produtos de tal marca por parte de consumidores. Portanto, o patrocínio tem potencial de elevar a probabilidade de consumidores com alto envolvimento esportivo em adquirir um produto desta marca por meio de processos de cognição, além de torná-los, no longo prazo, embaixadores da marca, o que estaria no cerne da natureza das atividades de marketing.

\section{Procedimentos metodológicos}

A pesquisa qualitativa parte de aspectos de grande abrangência, que, ao longo do processo de investigação, começam a se determinar. Neste sentido, Yin (2010) enfatiza que este tipo de pesquisa envolve a captação de dados descritos em profundidade sobre indivíduos, lugares e processos interativos por meio do contato entre o pesquisador e seu objeto de estudo com o objetivo de compreender fenômenos a partir da complementaridade dos elementos ativos da situação pesquisada. Prodanov e Freitas (2013) indicam que, no caso da abordagem qualitativa, o pesquisador necessita de um trabalho mais intensivo de campo para se ter um contato direto com seu objeto de estudo. Assim, sendo o objetivo desta pesquisa de caráter predominantemente descritivo, os pesquisadores registram e descrevem os fatos sem interferir neles, visando identificar as características de determinado fenômeno (Pradanov \& Freitas, 2013). Para tanto, como método de coleta de dados, esta pesquisa utiliza a entrevista em profundidade, um recurso metodológico que busca, com base em teorias e pressupostos definidos pelo investigador, recolher respostas a partir da experiência de uma fonte selecionada por deter informações que se deseja conhecer (Stoecker, 1991).

Para Duarte (2008), a entrevista em profundidade é considerada uma técnica qualitativa que explora um assunto a partir da busca de informações, percepções e experiências de informantes para analisá-las e apresentá-las de forma estruturada. Esse tipo de técnica procura encontrar intensidade nas respostas, não-quantificação ou representação estatística. A entrevista como técnica de pesquisa exige elaboração e explicitação de procedimentos metodológicos específicos: o marco conceitual no qual se origina, os critérios de seleção das fontes, os aspectos 
Ocke, M. A. M., Bosquetti, M. A., \& Alexandre, G. V. (2021, set./dez.). Patrocínio esportivo e comunicação de marca: perspectivas de patrocinadores, gestores de marketing esportivo e atletas brasileiros do surfe profissional

de realização e o uso adequado das informações são essenciais para dar validade e estabelecer as limitações que os resultados possuirão (Yin, 2010).

A partir da proposta de Selltiz, Whrightsman e Cook (1987), a entrevista em profundidade é extremamente útil para estudos que tratam de conceitos, percepções ou visões para ampliar o conhecimento sobre a situação analisada. As entrevistas são classificadas com grande variedade de tipologias, geralmente caracterizadas como abertas, semi-abertas e fechadas, originárias, respectivamente, de questões não estruturadas, semi-estruturadas e estruturadas. A entrevista aberta é essencialmente exploratória e flexível, não havendo sequência predeterminada de questões ou parâmetros de respostas. A entrevista semi-aberta, utilizada neste trabalho, tem origem em uma matriz, um roteiro de questões-guia que dão cobertura ao interesse de pesquisa e que tem origem no problema de pesquisa. A entrevista fechada é realizada a partir de questionários estruturados, com perguntas iguais para todos os entrevistados, de modo que seja possível estabelecer uniformidade e comparação entre as respostas (Stoecker, 1991).

A amostra, em entrevistas em profundidade, não tem seu significado mais usual, o de representatividade estatística de determinado universo (Duarte, 2008). Está ligada à significação e à capacidade que as fontes têm de dar informações confiáveis e relevantes sobre o tema de pesquisa. Assim, a seleção dos entrevistados em estudos qualitativos tende a ser não probabilística por conveniência - quando as fontes são selecionadas por proximidade ou disponibilidade, ou intencional - quando o pesquisador faz a seleção por juízo particular, como conhecimento do tema ou representatividade subjetiva. Nesta pesquisa, a amostra é intencional face a proximidade de acesso aos informantes aliada à relevância para o estudo. Quivy e Campenhoudt (1992) propõem três categorias bastante abrangentes de interlocutores em entrevistas: a) docentes, investigadores especializados e peritos; b) testemunhas privilegiadas; c) público a que o estudo diz respeito. Ampliando esta classificação, Duarte (2008) propõe cinco tipos de informantes para entrevistas em profundidade conforme indicado no Quadro 1 a seguir. 
Ocke, M. A. M., Bosquetti, M. A., \& Alexandre, G. V. (2021, set./dez.). Patrocínio esportivo e comunicação de marca: perspectivas de patrocinadores, gestores de marketing esportivo e atletas brasileiros do surfe profissional

\section{Quadro 1}

Tipos de Fontes de Informação Para Entrevistas em Profundidade

\begin{tabular}{|l|l|}
\hline \multicolumn{1}{|c|}{ Tipo de Informante } & \multicolumn{1}{c|}{ Características } \\
\hline Especialista & $\begin{array}{l}\text { Pesquisador, acadêmico ou pessoa de grande } \\
\text { experiência/conhecimento no assunto, mas não } \\
\text { diretamente envolvida com o problema de pesquisa. }\end{array}$ \\
\hline Informante-chave & $\begin{array}{l}\text { Fontes de informação consideradas fundamentais } \\
\text { por estarem profunda e diretamente envolvidas com } \\
\text { os aspectos centrais da questão. }\end{array}$ \\
\hline Informante-padrão & $\begin{array}{l}\text { Fonte envolvida com o tema de pesquisa, mas que } \\
\text { pode ser substituída por outra sem que se espere } \\
\text { prejuízo na qualidade das informações obtidas. }\end{array}$ \\
\hline Informante complementar & $\begin{array}{l}\text { Fontes de oportunidade surgidas no decorrer da } \\
\text { pesquisa. }\end{array}$ \\
\hline Informante-extremista & $\begin{array}{l}\text { Aquele cuja percepção contraria as principais fontes } \\
\text { por motivos ideológicos, políticos, pessoais ou por } \\
\text { possuir visão muito particular do tema. }\end{array}$ \\
\hline
\end{tabular}

Fonte: Duarte (2008)

Isto posto, foram realizadas seis entrevistas com informantes-chave (Duarte, 2008), presenciais e por chamada de vídeo ao longo do segundo semestre de 2019, para que fosse possível analisar pontos específicos de cada participante na relação de patrocínio entre as partes. Para transcrição do áudio obtido nas entrevistas, o software Voicemeeter Virtual Audio Mixere foi utilizado para sistematizar a análise e o software Voyant Tools contribuiu na compreensão e interpretação dos dados, uma vez que esta ferramenta possibilita o cruzamento entre os dados obtidos por meio de nuvem e cluster de palavras conforme a quantidade e relação entre os termos citados pelos entrevistados.

As entrevistas foram realizadas com gestores de duas marcas que atuam no mercado de surfe, a primeira delas, Billabong, com forte presença no mercado nacional e internacional no âmbito da produção e comercialização de equipamentos, acessórios e surfwear, aqui representada pelo administrador Gustavo Menasce Goldman; e a marca Snapy Surfboards, fabricante de pranchas de surfe para o mercado brasileiro e também exportadora para o mercado europeu, gerenciada pelo shaper Carlos Alexandre Bartelt. Em seguida, foram entrevistados os empresários Luiz Felipe Borges diretor da agência de marketing esportivo G8 Sports Entertainment e Daniel Cortez, diretor da empresa Flow Sports Management, ambas detentoras de direitos de imagem e gestoras de carreira de atletas profissionais de diferentes modalidades esportivas no cenário mundial. Por fim, os atletas entrevistados, surfistas brasileiros integrantes da elite mundial do surfe profissional, foram Michael Rodrigues e Yago Abbas Dora. Todos os 
Ocke, M. A. M., Bosquetti, M. A., \& Alexandre, G. V. (2021, set./dez.). Patrocínio esportivo e comunicação de marca: perspectivas de patrocinadores, gestores de marketing esportivo e atletas brasileiros do surfe profissional

participantes da pesquisa permitiram formalmente a divulgação de seus nomes e empresas que representam para a finalidade deste estudo.

\section{Análise dos resultados}

Nesta seção, é apresentada a análise dos dados coletados por meio das seis entrevistas realizadas, sendo duas entrevistas com gestores de marcas patrocinadoras, duas entrevistas com empresários de marketing esportivo e duas entrevistas com atletas brasileiros de surfe profissional. Em primeiro plano, aparecem as análises individuais de cada entrevista sendo seguidas pela compilação das duas entrevistas de cada unidade de análise - marcas, managers e atletas. A análise triangulada das seis entrevistas é apresentada posteriormente na seção que discute os resultados encontrados.

\subsection{Marca patrocinadora: Billabong}

Criada na Austrália em 1973, a marca Billabong tem grande representatividade junto aos praticantes do esporte em todo o mundo e é líder de mercado no segmento surfwear na América Latina, mantendo constante seu programa de expansão ampliando o número de estabelecimentos pelo mundo e estendendo a gama de produtos reciclados, tendo como principal item de portfólio a confecção de calções de banho. No início do ano de 2018 a marca Billabong foi comprada pela empresa Boardriders pelo valor de US\$ 155 milhões (cerca de R\$ 501,5 milhões na época) segundo informações da agência de notícias Reuters. Essa negociação acabou consolidando uma gigante no setor do surfe, tendo em vista que a Boardriders já era detentora das marcas Quiksilver, Roxy e DC Shoes. Por sua vez, a Billabong detém as marcas $R V C A$, Element e Von Zipper, todas integrantes do segmento de esportes de prancha e da cultura surfe e skate.

Para que a Billabong conseguisse se tornar uma das gigantes do seu segmento, foi preciso que ela adotasse uma cultura forte na criação de vestuário e acessórios confortáveis e duráveis, direcionados para a prática de surfe; na confecção de vestuário atendendo aos mercados de surfe, skate, snowboard e wakeboard, destinando-se ao sexo masculino e feminino, adulto e infantil. A identidade da marca agrega valores que giram em torno do espírito aventureiro que caracteriza o lifestyle da cultura surfe; amor e respeito pela natureza, em especial pelas praias e oceanos; sensibilidade às causas ambientais e de reciclagem; uso de materiais resistentes para oferecer o melhor corte de calções de banho do mercado. Neste 
Ocke, M. A. M., Bosquetti, M. A., \& Alexandre, G. V. (2021, set./dez.). Patrocínio esportivo e comunicação de marca: perspectivas de patrocinadores, gestores de marketing esportivo e atletas brasileiros do surfe profissional

sentido, a marca busca ser referência no âmbito dos esportes de prancha apoiando e incentivando a prática do esporte por meio de patrocínio em atletas, eventos e competições.

A Billabong já patrocinou grandes atletas da história do surfe, sendo o principal deles, o havaiano Andy Irons, uma das principais referências do esporte, conquistando três títulos mundiais ao longo da sua carreira. Atualmente, a marca patrocina e co-patrocina oito atletas, brasileiros e estrangeiros, tanto na elite do surfe mundial, composta pelos 36 melhores competidores, quanto na divisão de acesso onde qualquer surfista profissional pode participar. Conforme esclarece o gestor da marca entrevistado, Gustavo Menasce Goldman, ambas as modalidades, patrocínio e co-patrocínio, se diferenciam em razão do investimento feito:

"O atleta patrocinado recebe um investimento maior, ganhando seu salário mensal, recurso financeiro o qual é utilizado para disputar suas competições e arcar com os custos relativos à prática do esporte. Já o atleta co-patrocinado recebe apenas uma quantidade de roupas e acessórios já estabelecidos em contrato. Porém, ambos precisam realizar a divulgação da marca com as roupas e adesivos. Damos tudo que o atleta precisar em termos de apoio físico, monetário ou mental. Queremos o melhor do nosso atleta"

Um fator relevante é que a Billabong, sendo uma das marcas mais presentes no surfe mundial e investindo há muito tempo no patrocínio de atletas ainda não consegue mensurar o retorno sobre o investimento em patrocínio, sendo assim, a marca busca potencializar o retorno sobre o investimento por meio de diferentes ativações de marketing:

"Não conseguimos monetizar. Por mais que os nossos atletas estejam expostos nas mídias, não conseguimos comprovar que os consumidores passaram a comprar mais produtos da marca em razão disso. Então, observamos a exposição da marca em mídias e campeonatos. Além disso, desenvolvemos vídeos, sessão de autógrafo, posters, ação em loja para movimentar e campanhas em redes sociais".

A imagem que a marca Billabong busca passar para seu público, considerando o investimento realizado nos patrocínios em atletas de alta performance de diversos países, é a de marca vencedora com foco nos resultados dos atletas em competições oficiais. Ainda, a marca espera do atleta uma conduta adequada fora do âmbito das competições:

"Marca vencedora. Nossos atletas são referências no esporte, consequentemente, os consumidores passam a associar a imagem da marca como vencedora também, Resultado em campeonatos. Essa é uma das diretrizes da marca. Billabong é marca vencedora".

"A partir do momento em que um atleta passa a ser patrocinado, ele precisa ter uma postura exemplar tanto no surfe quanto na vida social dele, ou seja, andando na farmácia, no dentista ou onde quer ele for. O patrocínio não se resume somente quando ele pratica o esporte. Ele vai viver a marca e precisa sempre passar a melhor imagem possivel para os nossos consumidores". 
Ocke, M. A. M., Bosquetti, M. A., \& Alexandre, G. V. (2021, set./dez.). Patrocínio esportivo e comunicação de marca: perspectivas de patrocinadores, gestores de marketing esportivo e atletas brasileiros do surfe profissional

\subsection{Marca patrocinadora: Snapy Surfboards}

A Snapy Surfboards é uma empresa brasileira que surgiu no estado de Santa Catarina no ano de 2005. Fundada por Carlos Alexandre Bartelt, a partir de sua oficina de conserto de pranchas, a marca fabrica pranchas de surfe comercializando no mercado doméstico e exportando para o continente europeu. A missão da Snapy Surfboards está embasada na dedicação para fazer pranchas de surfe de alta performance para todos os tipos de atletas, amadores e profissionais, na busca por ser referência nacional pelo design e qualidade dos seus produtos, tendo como conceitos norteadores a excelência em inovação e P\&D, originalidade e excelência no atendimento e satisfação dos clientes. Neste cenário, a marca vem crescendo e ganhando notoriedade no mercado brasileiro de surfe. Para o fundador da empresa, essa evolução ocorre em razão de alguns fatores, tais como: qualidade dos seus materiais e pelas conquistas dos atletas patrocinados pela marca nos campeonatos nacionais e internacionais, o que resulta em uma positiva imagem de marca no mercado do surfe.

Atualmente, a marca investe em ações de patrocínio em nove atletas. Destes, quatro são competidores profissionais, dois são freesurfers (surfistas não competidores) e três "local heroes", pessoas influentes na região de Santa Catarina, mais especificamente na cidade de Balneário Camboriú - SC. Carlos Alexandre Bartelt destaca as diferenças nestes formatos de patrocínio:

"Os competidores precisam de mais suporte da marca, sendo assim, costumam ganhar mais pranchas e produtos de melhor qualidade. Os demais ganham uma quantidade menor de pranchas, porém, todos precisam atuar com a divulgação da marca. A Snapy patrocina dando a prancha de surfe. Não damos dinheiro para os nossos atletas além dos equipamentos. Porém, sempre avaliamos caso a caso para verificar onde podemos ajudar. Normalmente somente pranchas".

Assim como observado com a marca Billabong, a Snapy Surfboards não utiliza qualquer métrica quantitativa para avaliar os resultados obtidos com as ações de patrocínio.

"Não conseguimos monetizar o retorno financeiro através do patrocínio. É tiro no escuro, muitas das vezes a empresa pode ter prejuízo, ou, ganhar bastante dinheiro através do financeiro. Porém, avaliamos através de resultados e relação com os consumidores através de campanhas publicitárias com os próprios atletas. A mesma dificuldade que se tem de prever o retorno através do investimento em outdoor, por exemplo, é a dificuldade contida na utilização de um patrocínio. Então, acredito que os atletas acabam sendo embaixadores da marca, e, verificar que as pessoas falam bem do atleta, engajamento de consumidores através de redes sociais, e, claro, os resultados em competições também”. 
Ocke, M. A. M., Bosquetti, M. A., \& Alexandre, G. V. (2021, set./dez.). Patrocínio esportivo e comunicação de marca: perspectivas de patrocinadores, gestores de marketing esportivo e atletas brasileiros do surfe profissional

Neste sentido, a Snapy Surboards compreende o investimento em patrocínio bem sucedido e vantajoso não apenas nos resultados dos atletas, mas também na exposição da marca em diferentes meios de comunicação e ativações:

"Acredito que a interação entre o atleta e a marca, como ele se dedicou a empresa, resultados obtidos. Muitas vezes ele pode ter ido super mal nas competições, mas, percebendo que ele faz todo o trabalho com mídias sociais, cooperando com a marca em outros aspectos pode ser válido também, se sentindo como parte integrante da empresa. Mídias digitais, sessão de autógrafos, levar os atletas em lojas, levá-los até a empresa para trazer consumidores e assim por diante".

\subsection{Análise das marcas patrocinadoras}

Com base nas duas entrevistas realizadas com os gestores das marcas Billabong e Snapy Surfboards, o software Voyant Tools nos auxilia na análise de nuvem de palavras que compila os principais termos observados na coleta dos dados conforme demonstrado na Figura 1 a seguir.

\section{Figura 1}

Nuvem de Palavras

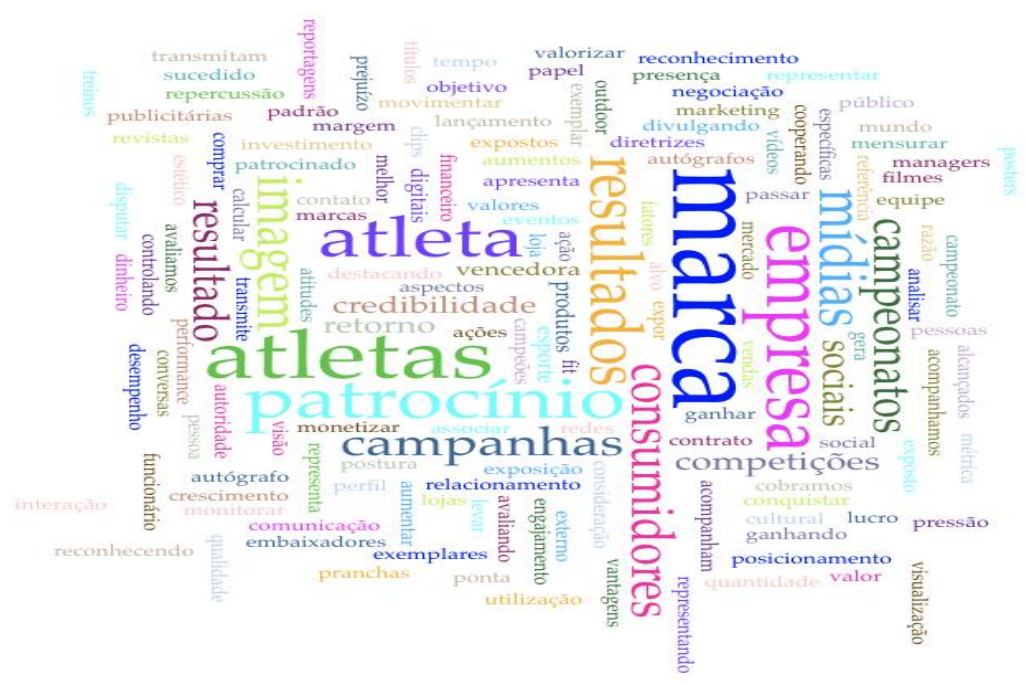

Fonte: Entrevistas com gestores de marcas patrocinadoras. Software Voyant Tools.

Os principais termos citados foram: "marca", "empresa", "resultados", “consumidores" e "mídias". Logo, de acordo com os pontos observados nas entrevistas, o principal fator levado em consideração por gestores das marcas patrocinadoras em relação ao retorno sobre investimento e objetivos de patrocínio em atletas de surfe giram em torno dos 
Ocke, M. A. M., Bosquetti, M. A., \& Alexandre, G. V. (2021, set./dez.). Patrocínio esportivo e comunicação de marca: perspectivas de patrocinadores, gestores de marketing esportivo e atletas brasileiros do surfe profissional

resultados obtidos pelos atletas e exposição da marca em diferentes mídias. De forma complementar, é possível expandir esta análise para encontrar aderência entre os termos mais citados ao longo das entrevistas conforme representado na Figura 2.

Figura 2

Aderência entre os Termos Citados

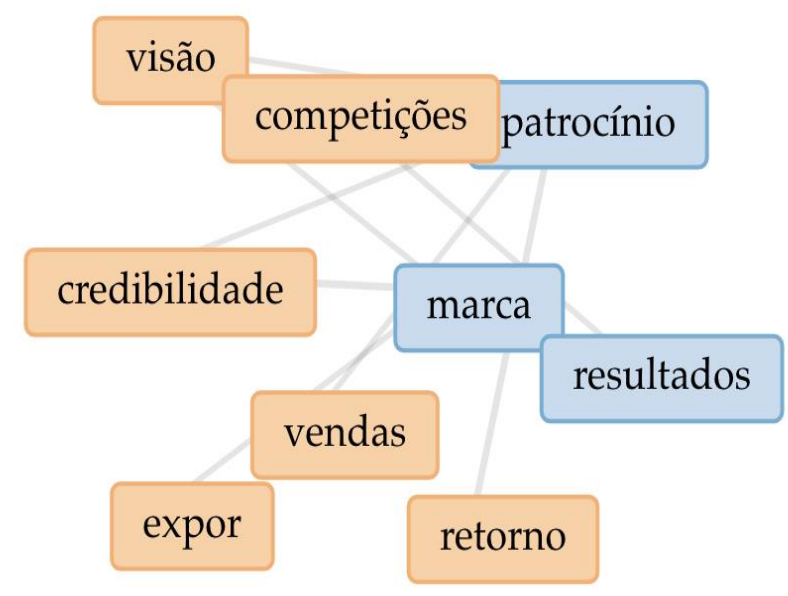

Fonte: Entrevistas com gestores de marcas patrocinadoras. Software Voyant Tools.

Novamente, é possível observar que um dos termos centrais obtido nas entrevistas com os gestores de marcas patrocinadoras Billabong e Snapy Surfboards é “resultados ”, diretamente relacionado aos termos "patrocínio" e "credibilidade". Assim, é possível depreender que o objetivo das empresas nos investimentos em ações de patrocínio trata da relação existente entre os bons resultados obtidos pelos atletas nas competições com o aumento da notoriedade e credibilidade da marca junto aos consumidores, o que, por sua vez, pode resultar em retorno financeiro com aumento das vendas. Pode-se ainda compreender que as ações de comunicação de marca em mídias sociais e demais ativações de marca atuam como elementos complementares para estabelecer a relação de imagem vencedora estabelecida entre marcas e atletas.

\subsection{Agência de marketing esportivo: G8 sports entertainment}

Fundada no ano de 2013, a G8 Sports Entertainment, agência de marketing esportivo, possui como missão conectar ideias e transformá-las em projetos vencedores. Além disso, possui uma visão global acerca de temas relacionados à gestão esportiva, tendo em vista que 
Ocke, M. A. M., Bosquetti, M. A., \& Alexandre, G. V. (2021, set./dez.). Patrocínio esportivo e comunicação de marca: perspectivas de patrocinadores, gestores de marketing esportivo e atletas brasileiros do surfe profissional

atuam com diversas atividades pertinentes a este segmento, tais como: planejamento em comunicação, ativação e captação de patrocínio, eventos, consultoria e elaboração de projetos de lei de incentivo. Relacionando a G8 Sports Entertainment com o surfe, a empresa agencia atletas renomados, dentre eles, Adriano de Souza, campeão mundial de surfe no ano de 2015 da WSL conforme apresentado no Quadro 3 a seguir.

\section{Quadro 3}

Atletas Agenciados Pela G8 Sports Entertainment

\begin{tabular}{|c|c|}
\hline Atletas Brasileiros Patrocinados & Categoria Profissional 2019 \\
\hline Adriano de Souza & $\begin{array}{c}\text { Elite mundial do Surfe. Campeão Mundial } \\
2015\end{array}$ \\
\hline Willian Cardoso & \begin{tabular}{c} 
Elite mundial do Surfe. \\
\hline Lucas Vicente
\end{tabular} \\
\hline Tatiana Weston-Webb & $\begin{array}{c}\text { Divisão de acesso à elite mundial do surfe. } \\
\text { Campeão Mundial Pró-Júnior 2019. }\end{array}$ \\
\hline Silvana Lima & $\begin{array}{c}\text { Elite mundial do Surfe Feminino } \\
\text { Elite mundial do Surfe Feminino }\end{array}$ \\
\hline Tainá Hinckel & $\begin{array}{c}\text { Divisão de acesso à elite mundial do surfe } \\
\text { feminino }\end{array}$ \\
\hline
\end{tabular}

Fonte: Elaborado pelos autores.

Conforme pode-se observar, a G8 Sports Entertainment possui relevância na administração de carreira e patrocínio de atletas brasileiros competidores no surfe mundial. Para Luiz Felipe Borges, diretor da agência, as ações de patrocínio vêm se transformando ao longo do tempo, principalmente no que diz respeito à relação entre os atletas e seus seguidores em redes sociais tendo a marca patrocinadora como ativo estratégico destas relações:

"O patrocinio esportivo mudou muito. Antigamente o patrocínio era colocar uma camisa e uma logo e era suficiente. Hoje a exigência é muito maior. Os atletas precisam expor cada vez mais a marca, em razão de o mercado ser altamente competitivo. Além disso, os atletas passam a ser blogueiros, precisando se comunicar bem e ser bom em tudo o que fazem. Dessa forma, o atleta fica mais atento à comunicação e tudo mais”.

A captação de novos atletas para tratativas comerciais e os formatos de patrocínio são baseados no perfil do potencial patrocinado dentro e fora das competições, o que está alinhado com os discursos dos gestores das marcas patrocinadoras apresentadas na seção anterior. 
Ocke, M. A. M., Bosquetti, M. A., \& Alexandre, G. V. (2021, set./dez.). Patrocínio esportivo e comunicação de marca: perspectivas de patrocinadores, gestores de marketing esportivo e atletas brasileiros do surfe profissional

"Podem ser captados através de boca a boca (networking) ou procurando os atletas em matérias, praias e com resultados de campeonatos. Existe patrocínios onde a marca quer exposição na prancha, outros visam apenas exposição em mídias sociais. Tem também os apoios que é mais uma ajuda de custo".

"O atleta patrocinado passa a ser muito mais do que um funcionário, pois, representa a marca 24 por dia, onde quer que ele esteja".

Por mais difícil que seja mensurar o retorno sobre o investimento em ações de patrocínio, o entrevistado defende que as marcas patrocinem atletas, tendo em vista o retorno qualitativo que um atleta pode entregar à marca patrocinadora:

"Retorno pode existir ou não. Acredito que o retorno vem muito através de mídias sociais, através de eventos/competições que o atleta participa e passa a ser conhecido neste meio. Mas, muitas vezes o investimento não tem o retorno esperado. Dessa forma, a marca precisa explorar ao máximo a imagem do atleta com campanhas publicitárias, seja de forma física ou na forma digital. Pois o patrocínio amplia a comunicação entre marca e consumidores. $O$ marketing pode ser feito através de um anúncio de jornal, mídias sociais. Porém, o atleta possui seguidores fiéis, está sempre viajando para diversos lugares e isso acaba dando uma boa visibilidade ao atleta, e, consequentemente relaciona o atleta à marca"

\subsection{Agência de marketing esportivo: flow sports management}

A Flow Sports Management surgiu em 2017 com o objetivo de trabalhar com eficiência em ações de marketing esportivo com a nova geração do surfe brasileiro. Possui como missão garimpar talentos, investir na base, estruturar carreiras e gerenciar a imagem dos atletas de surfe profissional. A empresa conta com diversos atletas que atuam de forma influente no território brasileiro e até mesmo no cenário mundial. Além disso, costuma apostar tanto em atletas já consagrados no mercado, como também em atletas de base contribuindo para que um alcancem os seus objetivos. O Quadro 4 a seguir lista atletas de surfe agenciados pela Flow Sports Management.

\section{Quadro 4}

Atletas Agenciados Pela Flow Sports Management

(Continua)

\begin{tabular}{|c|c|}
\hline Atletas Brasileiros Patrocinados & Categoria Profissional 2019 \\
\hline Deivid Silva & Elite mundial do Surfe. \\
\hline Alex Ribeiro & $\begin{array}{c}\text { Divisão de acesso à elite mundial do surfe. } \\
\text { Ingresso na elite em 2020. }\end{array}$ \\
\hline Wigolly Dantas & Divisão de acesso à elite mundial do surfe. \\
\hline
\end{tabular}


Ocke, M. A. M., Bosquetti, M. A., \& Alexandre, G. V. (2021, set./dez.). Patrocínio esportivo e comunicação de marca: perspectivas de patrocinadores, gestores de marketing esportivo e atletas brasileiros do surfe profissional

\begin{tabular}{|c|c|}
\hline Wesley Dantas & Divisão de acesso à elite mundial do surfe. \\
\hline Yuri Gonçalves & Divisão de acesso à elite mundial do surfe. \\
\hline Wesley Santos & Divisão de acesso à elite mundial do surfe. \\
\hline
\end{tabular}

Fonte: Elaborado pelos autores.

O diretor da Flow Sports Management, Daniel Cortez, foi entrevistado para que fosse possível ter uma visão mais ampla de como a agência trabalha como moderadora dos diferentes formatos e ações de patrocínio em atletas brasileiros do surfe profissional:

"Os patrocínios são captados através de duas maneiras. A primeira delas, a marca vem com o interesse de patrocinar um determinado atleta e o empresário faz a ponte. A segunda maneira é: analisamos o perfil e a necessidade de um determinado atleta e verificamos que uma marca poderia combinar com ele, assim, entramos em contato para verificar a possibilidade de firmar este patrocínio”.

Na real possibilidade de efetivação de um contrato de patrocínio com um atleta, ambas as partes (surfista e marca) precisam definir seu formato e relações de contrapartida:

"Existem diversos tipos de patrocínios e co-patrocínio. Ao patrocinar um atleta a marca tem o direito de utilizar o bico da prancha para colocar o adesivo com sua logo, sendo assim, acabam colocando mais recursos financeiros para o atleta. Além disso, os patrocínios podem se diferenciar de acordo com os produtos disponibilizados para divulgação. Normalmente, as marcas que patrocinam os atletas possuem um mix de produtos maior, como por exemplo: roupas próprias para o surfe, vestuários e assim por diante. Já os co-patrocínios acabam disponibilizando menos recurso financeiro ou produtos, e, ficam com adesivos nas laterais da prancha e, consequentemente, menos divulgação da marca também”.

Embora seja difícil mensurar o retorno sobre o investimento em patrocínio, tampouco monetizar este retorno, para o entrevistado, as marcas concentram esforços neste tipo de ação e utilizam diferentes maneiras que associem o atleta à marca e ao produto para obter bons resultados e retorno positivo para a marca:

"As marcas precisam patrocinar os atletas para dar retorno ao que a mesma capitaliza com o surfe. A marca explora e vive do surfe, dessa forma, retorna essa parcela para o próprio esporte. Além disso, mais uma maneira de tentar aumentar a visibilidade da marca. $O$ retorno pode ser observado de diferentes maneiras, através de mídias sociais, resultados em competições".

\subsection{Análise das agências de marketing esportivo}

Com base nas duas entrevistas realizadas com os gestores de carreira de atletas das agências de marketing esportivo G8 Sports Entertainment e Flow Sports Management, o 
Ocke, M. A. M., Bosquetti, M. A., \& Alexandre, G. V. (2021, set./dez.). Patrocínio esportivo e comunicação de marca: perspectivas de patrocinadores, gestores de marketing esportivo e atletas brasileiros do surfe profissional

software Voyant Tools nos auxilia na análise por meio de nuvem de palavras que compila os principais termos observados na coleta dos dados conforme demonstrado na Figura 3 a seguir.

Figura 3

Nuvem de Palavras

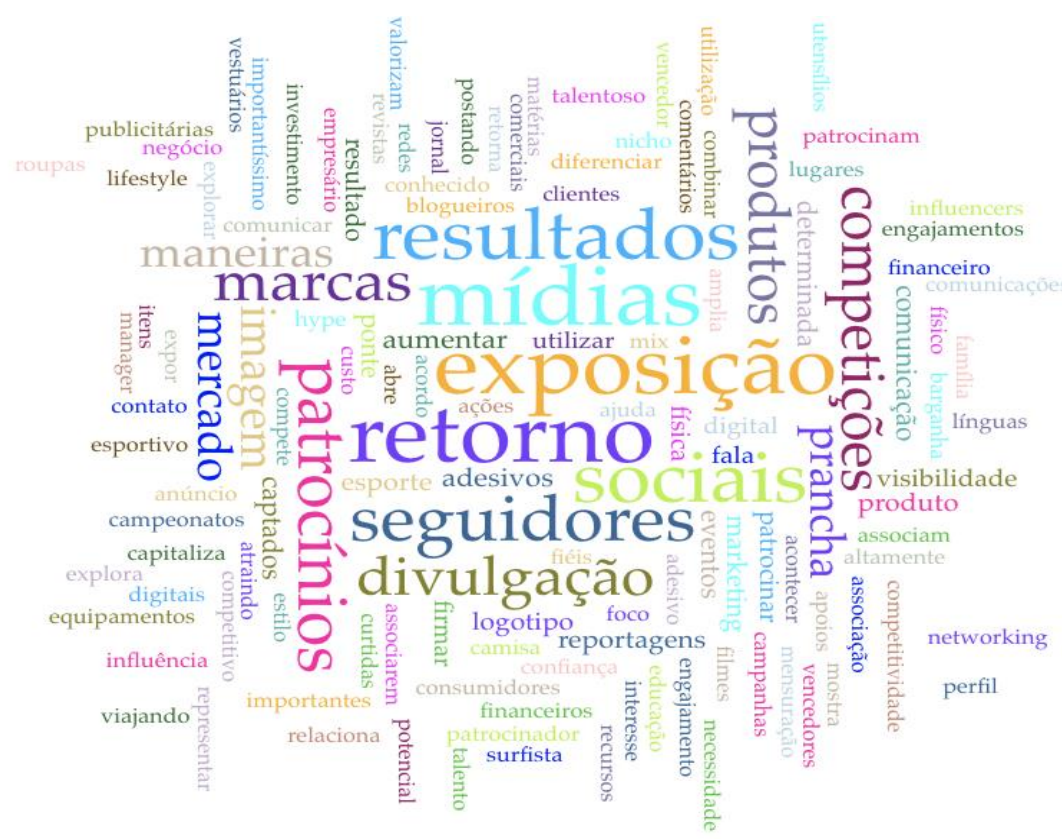

Fonte: Entrevistas com gestores de agências de marketing esportivo. Software Voyant Tools.

Nota-se um alinhamento entre o discurso dos empresários de carreira de atletas com os gestores de marcas patrocinadoras, uma vez que o termo "resultado" esteve presente de forma significativa. No entanto, destacam-se termos e palavras relacionadas com "exposição", ou seja, diretamente relacionado à "divulgação" e "seguidores". Assim, é possível afirmar que, na perspectiva das agências de marketing esportivo, o patrocínio é uma iniciativa que as marcas utilizam para que consigam aumentar a divulgação da sua marca por meio dos atletas, onde, no caso de apresentarem boas performances em seus treinos e campeonatos, resultarão em um aumento da divulgação da marca patrocinadora o que pode ser representado na Figura 4 a seguir. 
Ocke, M. A. M., Bosquetti, M. A., \& Alexandre, G. V. (2021, set./dez.). Patrocínio esportivo e comunicação de marca: perspectivas de patrocinadores, gestores de marketing esportivo e atletas brasileiros do surfe profissional

Figura 4

Aderência Entre os Termos Citados

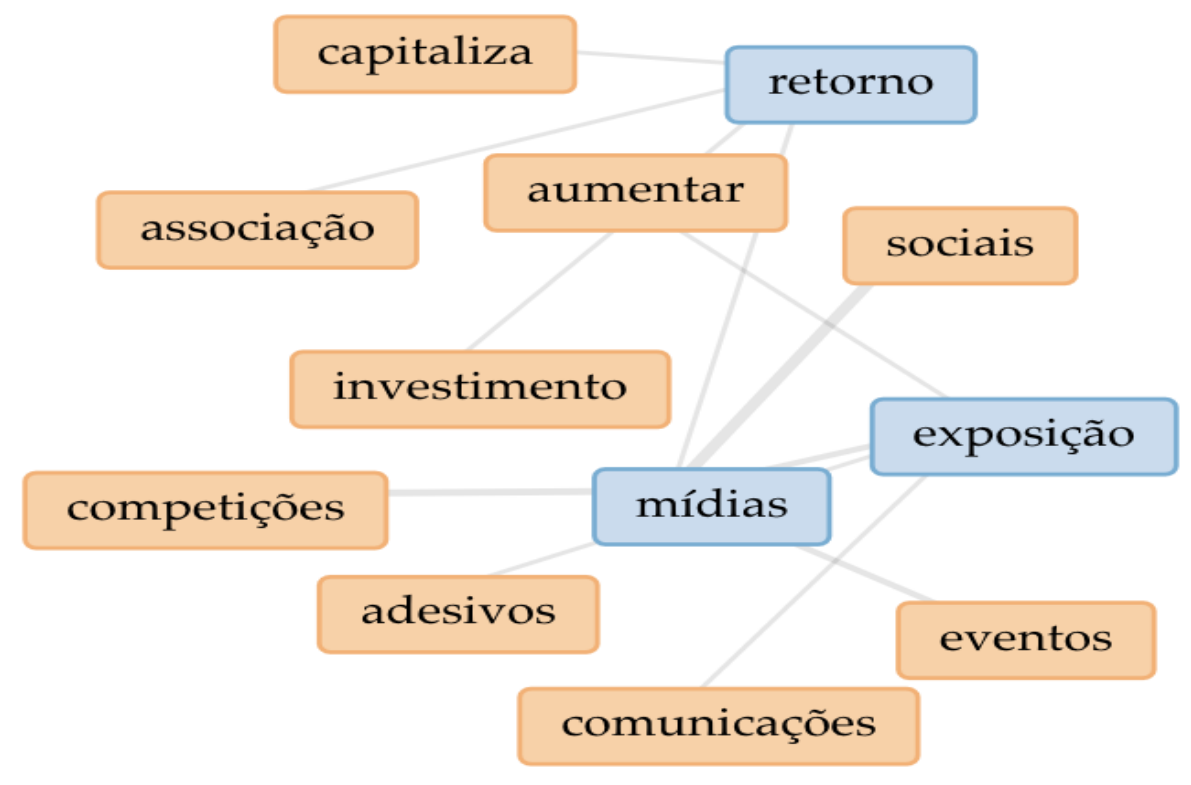

Fonte: Entrevistas com gestores de agências de marketing esportivo. Software Voyant Tools.

Na perspectiva dos empresários de marketing esportivo, a eficiência do patrocínio está diretamente ligada ao retorno que a marca obtém com o investimento por meio de bons resultados alcançados pelos atletas. Porém, na ligação entre os termos citados, nota-se que muitos pontos se relacionam diretamente com comunicação/exposição, ou seja, adesivos, eventos, comunicações, entre outros. É possível compreender, então, que a exposição da marca ocorre por meio de diferentes mídias e de maneira física também, tendo em vista que os atletas utilizam todos os equipamentos, vestuário, acessórios e adesivação de prancha da marca patrocinadora. Assim, observa-se que na visão dos managers, o principal objetivo das marcas com o patrocínio em atletas está ligado à comunicação da marca com seu público-alvo tendo os atletas como um canal eficiente de comunicação.

\subsection{Atleta profissional: Michael Rodrigues}

O surfista profissional Michael Rodrigues, 24 anos, é natural do Ceará e radicado em Florianópolis - Santa Catarina. O atleta ingressou na elite do surfe mundial no ano de 2018 e concluiu a temporada de 2019 em $26^{\circ}$ lugar e vem competindo para se manter entre os dez primeiros colocados nos próximos anos. Para isso, conta com patrocínio e co-patrocínios 
Ocke, M. A. M., Bosquetti, M. A., \& Alexandre, G. V. (2021, set./dez.). Patrocínio esportivo e comunicação de marca: perspectivas de patrocinadores, gestores de marketing esportivo e atletas brasileiros do surfe profissional

internacionais e locais. Para o atleta, o investimento de marcas patrocinadoras é fundamental para o alcance de objetivos em comum:

"Ter uma empresa acreditando no seu trabalho é essencial para um atleta com objetivos, ajuda tanto na parte financeira como na parte mental de saber que estar representando uma marca que acredita no seu potencial Trabalho duro, todos os lados cumprirem suas partes, acreditando sempre no objetivo final, que não é da noite para o dia e nem muito menos em um ano".

No que diz respeito aos objetivos e planejamento da carreira, o atleta enfatiza que as marcas patrocinadoras não têm participação direta, ou seja, os objetivos são estipulados pelo próprio atleta junto à sua equipe técnica:

"Eu estipulo essas metas juntamente a minha equipe - manager, treinador, preparador fisico, nutricionista, médico e etc".

A entrevista indica também, sob a perspectiva do atleta, a dificuldade em avaliar quantitativamente o retorno do investimento em patrocínio, corroborando o que foi observado no relato dos entrevistados das demais categorias de análise, apontando para a exposição da marca por meio de competições e demais ativações como principais instrumentos de comunicação de marca:

"Sou um atleta competitivo, hoje em dia posso oferecer a marca, mídia através do tour mundial que é assistido por $90 \%$ dos usuários do esporte, meu dia a dia de treinos e viagens que é um "lifestyle" que as pessoas curtem hoje em dia".

"Captação de mídia através de vídeos que mostrem o produto que a marca vende sendo utilizado no dia a dia do atleta, entrevistas, interação com o público através de eventos promovidos pela marca, marketing em mídias sociais, logomarca na prancha e muitas outras ideias que cabem ao marketing da marca promover"

\subsection{Atleta profissional: Yago Dora}

O surfista profissional Yago Dora, 23 anos, é natural de Curitiba - PR e reside na cidade de Florianópolis - SC. É um dos surfistas mais inovadores do circuito mundial de surfe e possui alguns títulos relevantes em sua carreira. Finalizou a temporada de $2019 \mathrm{em} 22^{\circ}$ lugar da elite mundial do surfe, porém vem buscando maior regularidade para que possa alcançar melhores resultados, sempre contando com a participação de marcas nacionais e internacionais como patrocinadoras e co-patrocinadoras. Para o atleta, o investimento das marcas no esporte, nas competições e nos atletas é essencial para que possam prosperar na carreira: 
Ocke, M. A. M., Bosquetti, M. A., \& Alexandre, G. V. (2021, set./dez.). Patrocínio esportivo e comunicação de marca: perspectivas de patrocinadores, gestores de marketing esportivo e atletas brasileiros do surfe profissional

"O patrocínio é o que nos dá a condição de viajar para competir e seguir uma carreira no surfe. Os contratos possuem bonificações que nos incentivam a atingir metas em conjunto com as marcas patrocinadoras".

"Uma relação de respeito para chegar a um contrato ideal para todos os lados, relação com a marca, e retorno do atleta para a marca, ou seja, atleta tenha boas condições para competir e se desenvolver e a marca tendo retorno com resultados e a imagem positiva do atleta".

Observa-se que as marcas costumam utilizar a imagem dos atletas por meio de ações estruturadas de comunicação de marca, porém, pode ocorrer que esta exposição também aconteça de forma espontânea, resultado do bom desempenho dos atletas nas competições reverberando na mídia especializada e tradicional:

"Os resultados em campeonatos são, hoje em dia, os que mais trazem visibilidade para um surfista profissional, ou seja, muito importante para o atleta e para patrocinadores. Quanto mais você aparecer, mais a marca vai aparecer junto, assim, gerando grande visibilidade".

Por fim, o atleta destaca a presença digital da personalidade esportiva nas redes sociais e o poder de exposição da marca neste tipo de plataforma para gerar retorno para a marca patrocinadora e incentivo ao atleta profissional:

"Ser influente aumenta seu alcance com o seu público, seus fãs. Ter uma rede social forte influência muito na visibilidade de um atleta nos dias de hoje. Ações de marketing envolvendo o atleta, divulgação dos produtos por meio do atleta, o atleta tem que ser um atrativo para sua marca ser mais vendida".

"Acredito que é uma soma entre todas elas que fazem um atleta ser interessante para representar uma marca".

\subsection{Análise dos atletas profissionais}

Realizadas as duas entrevistas com os surfistas profissionais Michael Rodrigues e Yago Dora, a utilização do software Voyant Tools nos permite aprofundar a análise por meio da ferramenta de nuvem de palavras compilando os principais termos observados na coleta dos dados de acordo com a Figura 5 a seguir. 
Ocke, M. A. M., Bosquetti, M. A., \& Alexandre, G. V. (2021, set./dez.). Patrocínio esportivo e comunicação de marca: perspectivas de patrocinadores, gestores de marketing esportivo e atletas brasileiros do surfe profissional

\section{Figura 5}

Nuvem de Palavras

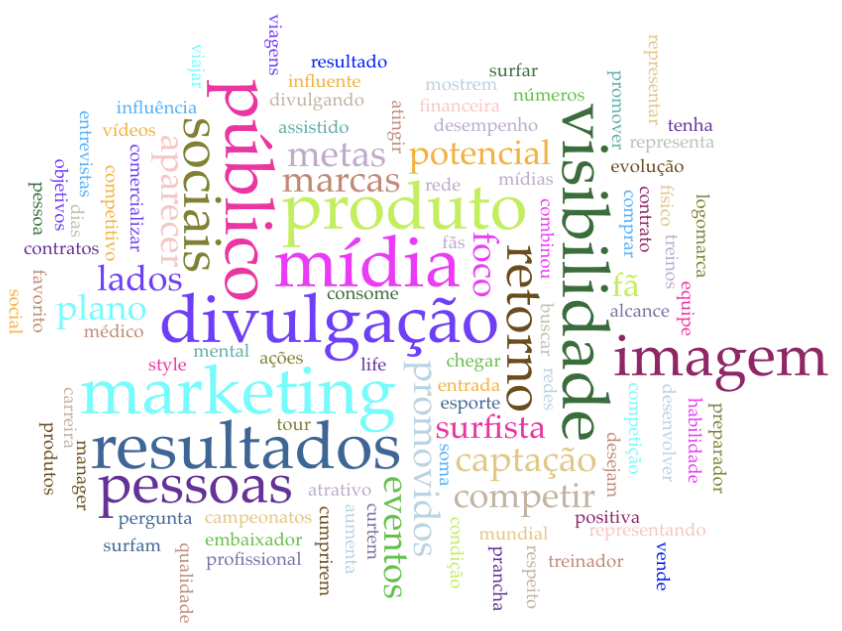

Fonte: Entrevistas com atletas profissionais. Software Voyant Tools.

Neste momento, é possível notar certa diferença em relação ao discurso de gestores de marcas e empresários de marketing esportivo, uma vez que, na perspectiva dos atletas, surgem mais termos relacionados à exposição de marca como "marketing", "mídia" e "divulgação". Entretanto, os termos aderentes ao resultado dos atletas nas competições tais como "desempenho" e "competição" também aparecem com frequência, corroborando os argumentos dos demais entrevistados. Observa-se, contudo, que a ligação entre os termos citados pelos atletas, conforme apresentado na Figura 6, está diretamente relacionada à divulgação e iniciativas de marketing.

Figura 6

Aderência Entre os Termos Citados

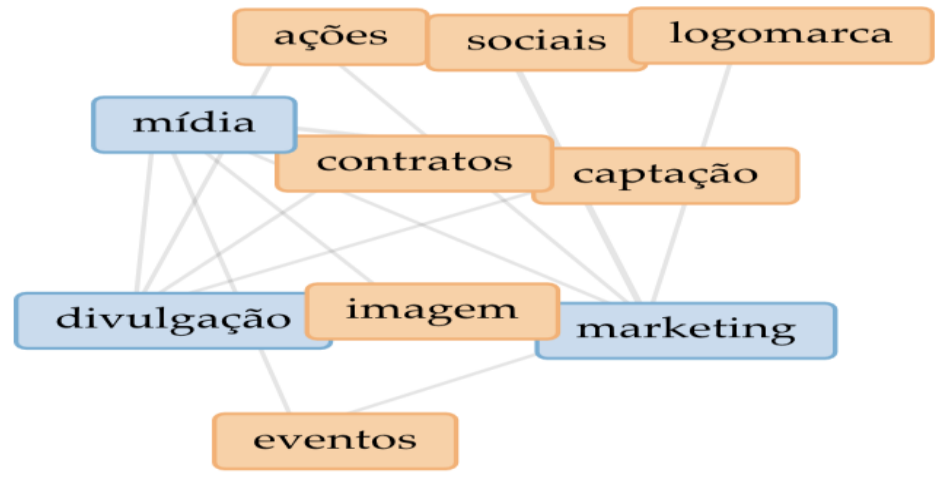

Fonte: Entrevistas com atletas profissionais. Software Voyant Tools. 
Ocke, M. A. M., Bosquetti, M. A., \& Alexandre, G. V. (2021, set./dez.). Patrocínio esportivo e comunicação de marca: perspectivas de patrocinadores, gestores de marketing esportivo e atletas brasileiros do surfe profissional

De acordo com os pontos observados, todas as ações de marketing realizadas pelas marcas têm como objetivo final a divulgação do patrocinador, resultando em uma possível captação de novos clientes, fortalecendo a marca junto a seu mercado consumidor. Dessa maneira, com as ações realizadas em eventos e mídias sociais as marcas atuam na busca do retorno sobre o investimento, tendo em vista que, como já mencionado outras vezes, existe grande dificuldade em mensurá-lo de outras formas.

\section{Discussão}

A análise conjunta dos dados coletados por meio das entrevistas realizadas com gestores de marcas patrocinadoras, empresários da área de marketing esportivo e atletas brasileiros competidores no circuito mundial de surfe, indicam grande alinhamento em relação aos objetivos traçados pelas três partes em um cenário de grande competitividade, tanto por parte dos atletas em busca de incentivos, como para as marcas que concorrem pela atenção e fidelidade de clientes. Para atletas e seus empresários, o aporte financeiro e de equipamento proporciona condições para que os competidores possam participar das etapas que ocorrem em diferentes localidades ao redor do mundo, além de contarem com acompanhamento de equipe técnica qualificada nas áreas de administração, psicologia, nutrição e fisiologia do exercício. Para as marcas, o principal objetivo do investimento em patrocínio trata da comunicação da marca por meio do atleta e seu alto potencial de exposição e credibilidade junto ao público-alvo da marca. Nesta simbiose, as imagens da marca e do atleta se integram, sempre buscando evidenciar as características vencedoras dessas duas unidades.

Pode ser observado forte presença do termo "resultados" nas entrevistas com as três unidades de análise e, na sequência, o termo "imagem" ganhando relevância. Neste sentido, ambos os fatores fazem com que um atleta seja um potencial patrocinado e aumente as possibilidades de renovação e ampliação de contratos de patrocínio em andamento. Resultados positivos nas competições geram repercussão orgânica e programática para exposição da marca em campanhas publicitárias, mídias sociais, reportagens, programas de TV, filmes e séries, tornando os atletas um produto da marca para que aumentem o engajamento dos consumidores e passando uma imagem de credibilidade da marca ao mercado. Entretanto, destaca-se a necessidade de o atleta zelar por sua imagem em cenários além do ambiente esportivo, evitando, assim, prejuízo para as partes envolvidas. 
Ocke, M. A. M., Bosquetti, M. A., \& Alexandre, G. V. (2021, set./dez.). Patrocínio esportivo e comunicação de marca: perspectivas de patrocinadores, gestores de marketing esportivo e atletas brasileiros do surfe profissional

O investimento em patrocínio nos atletas de surfe tem aumentado cada vez mais, tendo em vista o crescimento da popularidade do esporte e o número de praticantes e simpatizantes. Sendo assim, ao patrocinar ou agenciar um atleta, as marcas e managers esperam que o retorno seja adquirido por meio de bons resultados e consequentemente da divulgação do atleta e da marca em eventos, mídias sociais e competições. Entretanto, o entendimento sobre os diferentes formatos de comunicação de marca que podem ser explorados não apresentaram consenso ao longo das entrevistas realizadas. Embora grande flexibilidade no uso da imagem do atleta para dar visibilidade à marca, a característica experiencial nas ações de comunicação de marca ainda parece ter seu uso limitado à venda de produtos personalizados, sessões de autógrafo em posters, equipamentos e vestuário nas lojas físicas. Sendo assim, este campo permite maiores possibilidades para que as marcas utilizem a imagem do atleta buscando aumentar notoriedade e também o volume de vendas de produtos do portfólio da marca conforme apontado em estudos que associam o marketing experiencial aos formatos de patrocínio (Chavanat, Martinent \& Ferrand, 2009; Brakus, Schmitt \& Zarantonello, 2009; Fransen, Van Rompay \& Muntinga, 2013).

Por fim, todos os entrevistados alegaram dificuldade em conseguir fazer a mensuração direta e quantitativa do retorno sobre investimento em patrocínio. Este fato corrobora o trabalho de Ottoni e Montagner (2004), pois acaba fazendo com que exista uma distorção com relação às receitas de vendas obtidas através de um determinado atleta e impede que as marcas consigam estruturar melhor o investimento em marketing de patrocínio. Inclusive, em alguns casos, uma ação de patrocínio pode dar prejuízo à marca caso o atleta não consiga atingir os objetivos almejados na temporada de competições, conforme também destacam Sá e Almeida (2012).

Tendo em vista a maneira como é compreendido, o ROI está relacionado à exposição do atleta em campeonatos e mídias digitais e tradicionais e, desta forma, os itens citados nas entrevistas possuem relação ao se analisar se um patrocínio tem dado retorno ou, ao menos, atendido aquilo que se espera pelas partes envolvidas, no que tange os resultados que o atleta conquistou durante o tempo de vigência do contrato e às maneiras em que ele divulgou a marca. No entanto, levando em consideração a grande quantidade de marcas que vêm buscando utilizar o marketing de patrocínio para se comunicar com o seu público-alvo e a notória evolução nos investimentos realizados pelas empresas por meio de patrocínio esportivo em atletas, a falta de utilização de métricas para que os gestores de marketing tenham conhecimento da ferramenta 
Ocke, M. A. M., Bosquetti, M. A., \& Alexandre, G. V. (2021, set./dez.). Patrocínio esportivo e comunicação de marca: perspectivas de patrocinadores, gestores de marketing esportivo e atletas brasileiros do surfe profissional

em profundidade pode ser considerada uma lacuna no conhecimento da administração de marketing em função da dificuldade de gerenciar aquilo que não é possível medir.

\section{Considerações finais}

Conforme dados da ISA - International Surfing Association (2021), estima-se que, atualmente, há cerca de 27 milhões de surfistas no mundo, com destaque para as Américas que ficam com a maior fatia do planeta, com um total de 13,5 milhões, seguidos da Oceania e a Ásia, com 6,5 e 6 milhões, e a Europa e a África, com 4,5 milhões de surfistas em cada continente. Em 2019, a World Surf League, entidade que gerencia o surfe profissional mundial, relatou que o esporte cresce mais de $30 \%$ ao ano e que a indústria global do surfe gerou mais de US\$ 13 bilhões somente naquele ano (World Surf League, 2020). Nesta indústria, as atividades relacionadas à prática do esporte possuem desdobramentos diversos: a cadeia produtiva de equipamentos para sua prática, acrescida do exponencial crescimento do segmento surfwear ao longo dos últimos anos composto pela comercialização de vestuário e acessórios voltados à cultura surfe; a comercialização de destinos de surfe por agências de turismo especializadas; o impulsionamento da visibilidade do esporte pela mídia esportiva e tradicional no Brasil e no mundo, principalmente com o excelente desempenho de atletas brasileiros do surfe profissional, incluindo a conquista de quatro títulos mundiais nos últimos cinco anos (World Surf League, 2020).

Neste cenário, o investimento em patrocínio esportivo é crescente no Brasil, principalmente no que diz respeito ao patrocínio em atletas do surfe profissional, uma vez que o excelente desempenho de atletas brasileiros nas competições oficiais ao longo da última década aumentou a demanda por informações, equipamento, vestuário e cultura surfe. $\mathrm{O}$ patrocínio esportivo busca identificar e criar oportunidades de comunicação e relacionamento com seus mercados por meio de uma comunicação de marketing capaz de impactar significativamente o consumidor esportivo de forma eficiente, atuando em conjunto com ações de propaganda e outros formatos de comunicação integrada de marketing. A associação da imagem da marca patrocinadora com a imagem da equipe, evento ou atleta patrocinado potencializa o valor agregado das duas entidades - patrocinador e patrocinado - e impacta positivamente o comportamento do consumidor esportivo.

Este artigo apresentou a relação estabelecida entre as partes envolvidas em um patrocínio dentro do cenário de surfe profissional - marcas patrocinadoras, empresários de 
Ocke, M. A. M., Bosquetti, M. A., \& Alexandre, G. V. (2021, set./dez.). Patrocínio esportivo e comunicação de marca: perspectivas de patrocinadores, gestores de marketing esportivo e atletas brasileiros do surfe profissional

marketing esportivo e atletas brasileiros profissionais. Por meio da análise de seis entrevistas em profundidade, foram observadas as diferentes, porém aderentes, perspectivas no que diz respeito aos objetivos em comum, formatos de comunicação e ativações de marca que geram retorno para as três partes envolvidas. Destacam-se nos resultados apontados pela pesquisa, o desempenho obtido pelos atletas e sua capacidade de proporcionar visibilidade à marca como principais vetores de atratividade para os investimentos em patrocínio das marcas. Por outro lado, para atletas e profissionais de marketing esportivo, o apoio financeiro visando a manutenção de bons resultados nas competições é essencial para capitalizar a associação da imagem vencedora entre patrocinador e patrocinado.

No sentido de avançar no conhecimento sobre patrocínio esportivo dentro de sua realidade empírica-conceitual, este artigo contribui ao indicar que, para os envolvidos nos trâmites processuais do planejamento estratégico em ações de patrocínio, o retorno sobre o investimento neste tipo de atividade, está, de fato, relacionado qualitativamente ao nível de exposição da marca dentro de um composto de comunicação integrada do que, quantitativamente, numa relação de uso do patrocínio com aumento de vendas e lucratividade ou margem de marketing. Entretanto, nota-se uma subutilização de possibilidades mais amplas ne aplicação do patrocínio esportivo dentro de um espectro do marketing experiencial, assim como, o desenvolvimento de frameworks capazes de entregar às organizações métricas conclusivas que possam apoiá-las nas decisões estratégicas para investimento em patrocínio esportivo.

\section{Referências}

Afif, A. (2000). A bola da vez: o marketing esportivo como estratégia de sucesso. São Paulo: Infinito.

Alexander, N. (2009). Defining brand values through sponsorships. International Journal of Retail \& Distribution Management, 37(4), 346-357. https://doi.org/10.1108/09590550910948574

Brakus, J. J., Schmitt, B. H., \& Zarantonello, L. (2009). Brand Experience: What Is It? How Is it measured? Does It Affect Loyalty? Journal of Marketing, 73(3), 52-68. https://doi.org/10.1509/jmkg.73.3.052

Brown, G. (2000). Emerging Issues in Olympic Sponsorship: Implications for Host Cities. Sport Management Review, 3(1), 71-92. https://doi.org/10.1016/S1441-3523(00)70080-5 
Ocke, M. A. M., Bosquetti, M. A., \& Alexandre, G. V. (2021, set./dez.). Patrocínio esportivo e comunicação de marca: perspectivas de patrocinadores, gestores de marketing esportivo e atletas brasileiros do surfe profissional

Chakraborti, R., \& Roy, S. (2013). Meaning transfer between events and sponsor brands: Integrating the role of emotions - a new conceptual framework. Journal of Brand Strategy, 2(1), 87-105. Retrieved from:

https://www.ingentaconnect.com/content/hsp/jbs/2013/00000002/00000001/art00010

Chanavat, N., Martinent, G., \& Ferrand, A. (2009). Sponsor and Sponsees Interactions: Effects on Consumers' Perceptions of Brand Image, Brand Attachment, and Purchasing Intention, Journal of Sport Management, 23(5), 644-670. Retrieved Jul 31, 2021, from https://journals.humankinetics.com/view/journals/jsm/23/5/articlep644.xml

Crowley, M. G. (1991). Prioritizing the Sponsorship Audience. European Journal of Marketing, 25(11), 11-21. https://doi.org/10.1108/EUM0000000000628

Fransen, M.L., Rompay, T.J.L.v. and Muntinga, D.G. (2013), "Increasing sponsorship effectiveness through brand experience", International Journal of Sports Marketing and Sponsorship, Vol. 14 No. 2, pp. 37-50. https://doi.org/10.1108/IJSMS-14-022013-B004

Duarte, J. (2008) Entrevista em Profundidade. In: Duarte, J. \& Barros, A. (Eds) Métodos e Técnicas de Pesquisa em Comunicação. $2^{\mathrm{a}}$ Ed. São Paulo: Atlas.

Escobar, M. N. (2002). Patrocínio esportivo e seus efeitos sobre o valor da marca: um estudo exploratório no Brasil. (Dissertação de mestrado - EAESP-FGV). Recuperado de: http://hdl.handle.net/10438/5027

Fahy, J., Farrelly, F. and Quester, P. (2004), "Competitive advantage through sponsorship: A conceptual model and research propositions", European Journal of Marketing, Vol. 38 No. 8, pp. 1013-1030. https://doi.org/10.1108/03090560410539140

Farrelly, F., \& Quester. P. B. (2005) Examining important relationship quality constructs of the focal sponsorship exchange. Industrial Marketing Management, 34 (3), 211-219. https://doi.org/10.1016/j.indmarman.2004.09.003

Ferkins L. \& R. Garland (2006). Sport sponsorship. In: Sport business management in New Zealand. S. Leberman, C. Collins and L. Trenberth, (Eds). Thomson Publishing \& Dunmore Press (2nd Ed), Sydney. 3(8), 274-297.

Fernandes, A. (2009). Activação de Patrocínios Desportivos. Universidade de Lisboa 1-90. Recuperado de: https://repositorio.iscteiul.pt/bitstream/10071/1959/1/Tese\%20ACTIVA\%C3\%87\%C3\%83O\%20DE\%20PA TROCINIOS\%20DESPORTIVOS\%20-\%20Mestrado\%20em\%20Marketing.pdf

Geng, L., Burton, R. \& Blakemore, C. (2002). Sport sponsorship in China: transition and evolution. Sport Marketing Quarterly. 11(1). 20-32. Retrieved from: https://fitpublishing.com/content/sport-sponsorship-china-transition-and-evolution

Giroux, M., Pons, F. and Maltese, L. (2017), "The role of perceived brand personality in promotion effectiveness and brand equity development of professional sports 
Ocke, M. A. M., Bosquetti, M. A., \& Alexandre, G. V. (2021, set./dez.). Patrocínio esportivo e comunicação de marca: perspectivas de patrocinadores, gestores de marketing esportivo e atletas brasileiros do surfe profissional

teams", International Journal of Sports Marketing and Sponsorship, Vol. 18 No. 2, pp. 180-195. https://doi.org/10.1108/IJSMS-05-2017-092

Gwinner, K. and Swanson, S.R. (2003), "A model of fan identification: antecedents and sponsorship outcomes", Journal of Services Marketing, Vol. 17 No. 3, pp. 275294. https://doi.org/10.1108/08876040310474828

Horowitz, S. (2014). Does sports marketing work? How is it measured? Journal of Brand Strategy, 3(1), 41-50. Retrieved from: https://www.ingentaconnect.com/content/hsp/jbs/2014/00000003/00000001/art00007

ISA - International Surfing Association (2021). Disponível em: https://surftotal.com/noticias/exclusivos/item/15350-o-surf-no-mundo-em-numeros Acesso em 14 Jun 2021.

Mason, K. (2005) How corporate sport sponsorship impacts consumer behavior. The Journal of American Academy of Business, 7 (1), 32-35. Recuperado de http://www.jaabc.com/jaabcv7n1 preview.html

Mazzei, L. C., \& Rocco Jr., A. J. (2017). Um ensaio sobre a gestão do esporte: um momento para a sua afirmação no Brasil. Revista de Gestão e Negócios do Esporte, 2(1), 96109. Recuperado de: http://revistagestaodoesporte.com.br/mod/page/view.php?id=97

Melo Neto, F. (1995). Marketing esportivo. Rio de Janeiro: Record.

Meenaghan, T. (2001). Understanding Sponsorship Effects. Psychology \& Marketing. (1)8, 95-122. https://doi.org/10.1002/1520-6793(200102)18:2<95::AIDMAR1001>3.0.CO;2-H

Morgan, M. J.; Summers, J. (2008). Marketing Esportivo. São Paulo: Thomson Learning.

Navarro, A., Sicilia, M. and Delgado-Ballester, E. (2009), "Integrated marketing communications: Effects of advertising-sponsorship strategic consistency", EuroMed Journal of Business, Vol. 4 No. 3, pp. 223-236. https://doi.org/10.1108/14502190910992666

Neiva, E. R., \& Mauro, T. G. (2011) Atitudes e mudança de atitude. In C.V. Torres \& E.R. Neiva (Orgs.) Psicologia social: principais temas e vertentes. São Paulo: Artmed.

Ottoni, J. E., \& Montagner, P. C. (2004). Reflexões sobre metodologias de mensuração do retorno do investimento no esporte de competição a partir das contribuições teóricas publicadas. EFdeportes, 10(77). Recuperado de:

https://www.efdeportes.com/efd77/invest.htm

Parolini, P. \& Rocco Junior, A. (2016). Patrocínio Esportivo no Brasil: uma análise qualitativa da produção acadêmica brasileira sobre o tema. Revista Intercontinental de Gestão Desportiva - RIGD, Vol. 6, No 1 Recuperado de:

http://www.revista.universo.edu.br/index.php?journal=gestaoesportiva\&page=article $\&$ op=view \&path $\% 5 B \% 5 \mathrm{D}=2113 \&$ path $\% 5 \mathrm{~B} \% 5 \mathrm{D}=2437$

Prodanov, C. C. \& Freitas, E. C. (2013). Metodologia do Trabalho Científico: métodos e técnicas da pesquisa e do trabalho acadêmico. 2. ed. Novo Hamburgo: Feevale. 
Ocke, M. A. M., Bosquetti, M. A., \& Alexandre, G. V. (2021, set./dez.). Patrocínio esportivo e comunicação de marca: perspectivas de patrocinadores, gestores de marketing esportivo e atletas brasileiros do surfe profissional

Quivy, R. \& Campenhoudt, L. V. (1992). Manual de Investigação em Ciências Sociais. Lisboa: Gradiva.

Rezende, E. (2013). Patrocínio esportivo no Brasil movimenta $R \$ 665$ milhões. Disponível em: http://exame.abril.com.br Acesso em: 12 Nov 2019.

Roy, D. \& Cornewell, T. B. (2004). The effects of consumer knowledge on responses to event sponsorships. Psychology \& Marketing, (21)3, 185-207. https://doi.org/10.1002/mar.20001

Sá, B. \& Almeida, V. (2012). Motivação, Seleção, Ativação e Mensuração do Patrocínio Esportivo. V Encontro de Marketing ANPAD. Curitiba. Disponível em: https://docplayer.com.br/11968610-Motivacao-selecao-ativacao-e-mensuracao-dopatrocinio-esportivo.html

Silva, E. C. \& Las Casas, A. L. (2017). Sports Marketing Plan: Na Alternative Framework for Sports Club. International Journal of Marketing Studies, 9(4), 15-28. https://doi.org/10.5539/ijms.v9n4p15

Selltiz, C.; Whrightsman, L. S. \& Cook, S.W. (1987). Métodos de Pesquisa nas Relações Sociais. São Paulo: EPU.

Söderman, S. and Dolles, H. (2010), "Sponsoring the Beijing Olympic Games: Patterns of sponsor advertising", Asia Pacific Journal of Marketing and Logistics, Vol. 22 No. 1, pp. 8-24. https://doi.org/10.1108/13555851011013128

Smith, A. C., \& Stewart, B. (2007). The travelling fan: Understanding the mechanisms of sport fan consumption in a sport tourism setting. Journal of Sport \& Tourism, 12(3-4), 155-181. https://doi.org/10.1080/14775080701736924

Smolianov, P., \& Shilbury, D. (2005). Examining Integrated Advertising and Sponsorship in Corporate Marketing Through Televised Sport. Sport Marketing Quarterly, 14, 239250. Retrieved from: https://fitpublishing.com/content/examining-integratedadvertising-and-sponsorship-corporate-marketing-through-televised-sport

Stoecker, R. (1991). Evaluating and Rethinking the Case Study. The Sociological Review, 1(39), 88-112. https://doi.org/10.1111/j.1467-954X.1991.tb02970.x

Speed, R., Thompson, P. Determinants of sports sponsorship response. J. of the Acad. Mark. Sci. 28, 226-238 (2000). https://doi.org/10.1177/0092070300282004

WSL - World Surf League. (2020) - Disponível em https://asbmag.com/the-science-of-surfeconomics-explained/ Acesso em 14 Jun 2020. 